THU0049

CORRELATION BETWEEN IL-6 AND OSTEOCALCIN SERUM LEVELS WITH DISEASE ACTIVITY IN RHEUMATOID ARTHRITIS (RA) PATIENTS

Ervin Rapushi ${ }^{1}$, Teuta Backa ${ }^{1}$, Artur Zoto ${ }^{1}$, Ermira Zicishti ${ }^{1}$, Lediana Nuhaj ${ }^{1}$, Valbona Salko ${ }^{1}$, Indin Xhemali'. ' UHC "Mother Theresa", Rheumatology Service, Tirana, Albania; ${ }^{2}$ German Policlinic, Rheumatology Service, Tirana, Albania

Background: IL-6 plays a significant role in RA pathophysiology. It is considered nowadays as an important inflammation marker and it is responsible for a wide range of articular and extra-articular manifestations in RA patients. Osteocalcin is a protein (non collagenous) that can be found in the bones extracellular matrix, as well as in the circulating blood serum. This protein is a marker of bone formation and turnover.

Objectives: Evaluating IL-6 and osteocalcin serum levels in RA patients and their correlation with disease activity.

Methods: We examined 126 patients previously diagnosed with RA according to the ACR/EULAR 2010 criteria. To all patients it was measured the IL-6 serum level $(<4.0 \mathrm{pg} / \mathrm{mL})$, and also the osteocalcin serum level using the ELISA-OSTEO kit method (13-46ng/ml) and the disease activity was defined according to the DAS28. By using this activity score index the patients were divided in three groups: group I with active disease scoring > 5.1 (43 patients); group II with moderate disease activity scoring between 3.2 - 5.1 (52 patients); and group III with no disease activity scoring $<3.2$ (31 patients).

Results: IL-6 serum level resulted elevated in patients group I $(1.9 \pm 0.6 \mathrm{pg} /$ $\mathrm{ml} ;)$ and group II $(0.9 \pm 0.3 \mathrm{pg} / \mathrm{ml})$ and normal in patients group III $(0.35$ $\pm 0.1 \mathrm{pg} / \mathrm{ml})$. Osteocalcin serum level resulted elevated in the three groups but with higher serum levels in patients group I and II $(62 \pm 1.9 \mathrm{ng} / \mathrm{ml}$; $49.2 \pm 2.6 \mathrm{ng} / \mathrm{ml})$ and less higher serum levels in group III $(44.5 \pm 1.7 \mathrm{ng} / \mathrm{ml})$. IL-6 serum level correlates best with osteocalcin serum level in patients group I and II $(r=0.9)$. IL-6 serum level correlates with disease activity $(r=1)$. Osteocalcin serum level correlates with disease activity in group I and II ( $r=0.9)$ but not with disease activity in group III $(r=0.4)$.

Conclusion: There is a significant correlation between IL-6 serum level and disease activity according to DAS 28 in RA patients. The elevation of osteocalcin serum level correlates with disease activity in RA patients with high and moderate disease activity which is an important finding of the intense bone remodeling, whereas in patients with no disease activity bone remodeling tents to slow down.

Disclosure of Interests: None declared

DOI: 10.1136/annrheumdis-2019-eular.7650

\section{THU0050 IMPLICATIONS OF THE DIFFERENT RESPONSES OF NK CELLS AND MONOCYTES TO IL-6 AND IL-10 IN THE PATHOGENESIS OF ADULT-ONSET STILL'S DISEASE}

Kojiro Sato, Yoshimi Aizaki, Hiroaki Yazawa, Toshihide Mimura. Saitama Medical University, Department of Rheumatology and Applied Immunology, Saitama, Japan

Background: Adult-onset Still's disease (AOSD) is a systemic inflammatory disease, the cause of which is largely unknown. AOSD has recently been classified as one of the autoinflammatory diseases in which innate rather than acquired immunity plays an important role in the pathogenesis. Serum IL-18 has been shown to be highly elevated in AOSD patients [1,2].

Objectives: We attempted to quantify the levels of multiple cytokines in the serum of AOSD patients and to evaluate the effects of the cytokines detectable in the AOSD serum on natural killer (NK) cells and monocytes, since these are cells critical to innate immunity.

Methods: Our patients fulfilled Yamaguchi's criteria for the diagnosis of AOSD. We quantified the serum levels of 10 cytokines (IFN- $\alpha$, IFN- $\gamma$, IL$1 \beta$, IL-2, IL-4, IL-6, IL-10, IL-12p70, IL-17A and TNF- $\alpha$ ) using multiplex bead array assays and IL-18 using ELISA. We next sorted NK cells or monocytes from peripheral blood mononuclear cells of healthy controls and stimulated each of the cell populations in vitro in the presence of the cytokines that had been detected in the AOSD serum. We quantified the level of IFN- $\gamma$ in the culture supernatant by ELISA and assessed the surface expression level of tumor necrosis factor-related apoptosis-inducing ligand (TRAIL) on NK cells by flow cytometry. Intracellular staining of proinflammatory cytokines in monocytes was performed after stimulation with the same combinations of cytokines.

Results: The level of IL-18 was high in all of the AOSD samples tested. IL-6 was detectable in 8 out of 16 patients and IL-10 in 3 out of 16 . In contrast, serum IFN- $\gamma$ was not detected in any of the samples. When NK cells were stimulated in vitro with IL-18 alone, IFN- $\gamma$ was undetectable in the culture supernatant. The combination of IL-10 and IL-18, but not IL-6 and IL-18, induced IFN- $\gamma$. We evaluated the expression of the receptors for IL-6 and IL-10 on NK cells and found that IL-10R and IL$10 \mathrm{R} \beta$ were present, while IL-6R and gp130 were absent. The combination of IL-10 and IL-18 also induced TRAIL expression on NK cells in an IFN- $\gamma$-independent manner. In contrast, monocytes expressed both the IL-6 and IL-10 receptors. Monocytes stimulated with IL-6 expressed IL-1 $\beta$ and those stimulated with $\mathrm{IL}-18$ expressed IL-6; L-10 exhibited inhibitory rather than stimulatory effects on monocytes.

Conclusion: IL-18 alone did not induce the production of IFN- $\gamma$ from NK cells in vitro. The combination of $\mathrm{IL}-10$ and $\mathrm{IL}-18$, but not $\mathrm{IL}-6$ and $\mathrm{IL}$ 18 , induced the production of IFN- $\gamma$ and the surface expression of TRAIL on NK cells. In contrast, monocytes did express IL-6 receptors, and when stimulated with IL-6 or IL-18, produced various inflammatory cyto kines, which were inhibited, not stimulated, in the presence of IL-10. Thus, the same cytokines can exert very different effects on inflammation, which is partly explained by the specific expression of corresponding receptors.

\section{REFERENCES:}

[1] Kawashima M, et al., Arthritis Rheum. 2001;44(3):550-60.

[2] Yoshida Y, et al., Intern Med. 2011;50(16):1757-60

Disclosure of Interests: None declared

DOI: 10.1136/annrheumdis-2019-eular.5302

\section{THU0051 OFF-LICENCE USE OF ANAKINRA IN CRITICALLY ILL ADULTS WITH SUSPECTED HAEMOPHAGOCYTOSIS - A SINGLE CENTRE EXPERIENCE}

Shabnam Shabbir, Ahmad Al-Abdulla, Anne Kinderlerer, Mamta Sohal,

Mark Layton, Peter Hill, Richard Corbett, Liz Lightstone, Tom Cairns, Justin Mason, Nichola Cooper, Taryn Youngstein. Imperial College Healthcare NHS Trust, London, United Kingdom

Background: Anakinra is a recombinant interleukin-1 receptor antagonist licensed in Europe for the treatment of rheumatoid arthritis, periodic fever and auto-inflammatory syndromes ${ }^{1}$. It is increasingly recognised as an adjunct in the treatment of macrophage activation syndrome/secondary haemophagocytic lymphohistiocytosis $(\mathrm{HLH})^{2}$.

Objectives: To analyse the indication, patient demographic and outcomes of critically unwell patients receiving anakinra for suspected HLH.

Methods: Retrospective cohort analysis of adult patients who received anakinra over a 12-month period at Imperial College Healthcare NHS Trust, London.

Results: Eleven patients received anakinra (both sub-cutaneous and intravenous, dose range $100-460 \mathrm{mg}$ daily), ten alongside conventional treatments for $\mathrm{HLH}$. 64\% were male. Median age at presentation was 32 years (range 27-73 years). Serum ferritin was significantly elevated (median 17371 (range 4335 - 160,664 micrograms per litre) in all cases. Ten of eleven cases underwent bone marrow examination which showed haemophagocytosis in all cases. Underlying diagnoses were: T-cell Lymphoma $(n=3)$, Mantle Cell Lymphoma $(n=1)$, gastric MALT Lymphoma $(n=1)$, infection ( $n=3$ : Group A streptococcus in a patient with inflammatory arthritis (bone marrow not performed), EBV and CMV), retained products of conception $(n=1)$, post-transplant-related lymphoproliferative disorder in a case of systemic lupus with renal transplant $(n=1)$, unknown $(n=1)$.

Overall mortality was 55\%. The underlying diagnosis were: T -cell Lym phoma $(n=3)$, gastric MALT Lymphoma $(n=1)$, CMV infection in a post renal transplant immunosuppressed patient $(n=1$, sarcoidosis underlying diagnosis), unknown $(n=1)$. $100 \%$ of cases with T-cell lymphoma as the cause of HLH died, despite two of the three receiving standard chemo therapy to treat the lymphoma. The third case was diagnosed with non hepatosplenic gamma delta T-cell lymphoma post-mortem.

In the five cases that survived, anakinra led to rapid recovery in three cases (underlying diagnoses: Mantle Cell lymphoma (managed entirely steroid free), HLH secondary to retained products of conception, and inflammatory arthritis with Group A Streptococcal pneumonia). The two remaining cases had underlying PTLV and EBV-driven HLH. Anakinra led to rapid resolution of fever, improvement in respiration and dramatic decreases in serum ferritin (up to $98 \%$ reduction in three weeks).

There were no identifiable complications from anakinra use. One case remains on anakinra, a young male with inflammatory arthritis and Group A Streptococcus pneumonia, who rapidly flared again two days after ces sation with full recovery once anakinra was re-instigated.

Conclusion: Anakinra can be a useful adjunct in the treatment of suspected HLH but appears to be less efficacious in those with underlying haematological malignancy, where mortality remains high. In critically ill 
patients we have used it intravenously, and in higher doses, where the half-life is shorter and twice daily dosing is required.

Anakinra was well tolerated and its short half-life makes it ideal for use in suspected sepsis-driven HLH. One case was managed entirely steroidfree using anakinra. This allowed for the identification of an underlying lymphoma which may have missed had high-dose steroids been used. Larger studies will help us ascertain whether earlier anakinra use may spare steroid and chemotherapy side-effects and improve patient outcomes.

\section{REFERENCES:}

[1] Clinical Commissioning Policy: NHS England Reference: 170062P. 2018.

[2] Grom AA, et al. Nat Rev Rheumatol. 2016; 12(5): 259-268.

Disclosure of Interests: Shabnam Shabbir: None declared, Ahmad AlAbdulla: None declared, Anne Kinderlerer: None declared, Mamta Sohal: None declared, Mark Layton: None declared, Peter Hill: None declared, Richard Corbett: None declared, Liz Lightstone: None declared, Tom Cairns : None declared, Justin Mason Consultant for: Prof Mason has worked as a paid Consultant for Roche/Chugai and Novartis, Speakers bureau: Prof Mason has been a paid speaker for Roche/Chugai, Nichola Cooper: None declared, Taryn Youngstein: None declared DOI: 10.1136/annrheumdis-2019-eular.4245

\section{THU0052 USTEKINUMAB AND GUSELKUMAB TREATMENT RESULTS IN DIFFERENCES IN SERUM IL17A, IL17F AND CRP LEVELS IN PSORIATIC ARTHRITIS PATIENTS: A COMPARISON FROM USTEKINUMAB PH3 AND GUSELKUMAB PH2 PROGRAMS}

Stefan Siebert ${ }^{1}$, Matthew J Loza ${ }^{2}$, Qingxuan Song ${ }^{2}$, lain Mcinnes ${ }^{1}$, Kristen Sweet ${ }^{2}$ ${ }^{1}$ Institute of Infection, Immunity and Inflammation, University of Glasgow, Glasgow, United Kingdom; ${ }^{2}$ Janssen Research and Development, LLC, Spring House, United States of America

Background: Ustekinumab (UST) is a monoclonal antibody (mAb) that binds the p40 epitope which is shared by IL12 and IL23, whereas guselkumab (GUS) is a mAb that selectively binds the p19 subunit of IL23. In recent studies, both UST (Phase 3 programs) ${ }^{1}$ and GUS (Phase 2 program) ${ }^{2}$ have demonstrated a reduction in musculoskeletal clinical signs and symptoms and improvement of psoriatic lesions in patients with active psoriatic arthritis (PsA), implicating the IL12/23 pathway in disease pathogenesis.

Objectives: To explore the post-treatment pharmacodynamic changes of IL17A, IL17F, and CRP with GUS and UST in the context of PsA.

Methods: Serum protein levels of IL17A, IL17F, and CRP were measured in 142 subjects and 38 matched healthy controls from the GUS Ph2 study $^{2}$ at Weeks 0,4 , and 16 . In the UST Ph3 studies ${ }^{1}$, biomarkers were assayed at Weeks 0,4 , and 24 as follows: IL17A $(n=474)$, IL17F $(n=237)$, CRP ( $n=927)$. IL17A and IL17F were assayed using Single Molecule CountingTM Human Immunoassay Kits (formerly Singulex). CRP was measured using CardioPhase hsCRP assay (UST studies) or Meso Scale Discovery Platform (GUS study).

Results: At baseline, the Th17 effector cytokines IL17A and IL17F were elevated in the serum of PSA subjects in the GUS Ph2 cohort compared to healthy controls. IL17A and IL17F levels significantly correlated with affected skin body surface area, but not swollen or tender joint scores, in both studies. While none of the baseline levels of evaluated cytokines were associated with American College of Rheumatology (ACR) or Psoriasis Area Severity Index (PASI) clinical responses to UST, baseline IL17F levels were modestly associated with ACR20 response to GUS at week 24. Both UST and GUS treatment resulted in pharmacodynamic decreases in IL17A, IL17F, and CRP levels, with GUS treatment restoring IL17A and IL17F levels to that of healthy controls by week 16. Consistent with being a component of ACR scores, CRP changes were significantly associated with ACR20 responses to both UST and GUS treatment. Weeks 4 and 16 changes in IL17F with GUS treatment were significantly associated with ACR20 response at week 24. Week 24 PASI75 response to GUS was significantly associated with week 4 changes in IL17A, with a similar trend observed at Week 16.

Conclusion: These results underscore the relevance of the IL23/Th17 pathway in PSA, with GUS treatment providing a stronger suppression of the pathway than UST treatment. The significant associations of changes in IL17A and IL17F levels with GUS treatment with PASI75 and ACR20 response, respectively, support the importance of the IL23/Th17 pathway for both skin and joint pathologies. The associations of reduction in CRP levels with both UST and GUS treatment also reinforce the role of acute phase inflammation in joint pathology.
REFERENCES:

[1] Deodhar A, Kavanaugh A, et al. Lancet. 2013; 382(9894):780-9.

[2] Deodhar A, Gottlieb AB, et al. Lancet. 2018; 391(10136):2213-2224.

Disclosure of Interests: Stefan Siebert Grant/research support from: AbbVie, Novartis, Pfizer, Janssen, BMS, Celgene, UCB, and Boehringer Ingelheim, Consultant for: AbbVie, UCB, Pfizer, Janssen, Boehringer Ingelheim, Celgene, and Novartis, Speakers bureau: AbbVie, UCB, Pfizer, Janssen, Boehringer Ingelheim, Celgene, and Novartis, Matthew J Loza Shareholde of: Johnson \& Johnson, Employee of: Janssen Research \& Development, LLC, Qingxuan Song Employee of: Janssen Research \& Development, LLC, lain Mclnnes Grant/research support from: AstraZeneca, Celgene, Compugen, Novartis, Roche, UCB Pharma, Consultant for: AbbVie, Celgene, Galvani, Lilly, Novartis, Pfizer, UCB Pharma, Kristen Sweet Employee of: Janssen Research \& Development, LLC DOI: 10.1136/annrheumdis-2019-eular.479

\section{THU0053 APREMILAST INHIBITS THE TGFB1 MEDIATED TRANSITION OF CULTURED HUMAN SKIN FIBROBLASTS INTO PROFIBROTIC MYOFIBROBLASTS: IN VITRO STUDY}

Maurizio Cutolo ${ }^{1}$, Paola Montagna ${ }^{1}$, Giulia Martinelli ${ }^{1}$, Samuele Tardito ${ }^{1}$, Claudio Corallo ${ }^{2}$, Nicola Giordano ${ }^{2}$, Emanuele Cozzani ${ }^{3}$, Carmen Pizzorni ${ }^{1}$, Sabrina Paolino ${ }^{1}$, Massimo Patanè ${ }^{1}$, Alberto Sulli ${ }^{1}$, Elisa Alessandri ${ }^{1}$, Vanessa Smith ${ }^{4,5,6}$, Stefano Soldano ${ }^{1}$. 1 University of Genova, IRCCS Polyclinic San Martino Hospital, Research laboratory and Academic Division of Clinical Rheumatology, Department of Internal Medicine, Genoa, Italy; ${ }^{2}$ University of Siena Scleroderma Unit, Department of Medicine, Surgery and Neurosciences, Siena, Italy; ${ }^{3}$ University of Genova, IRCCS Polyclinic San Martino Hospital, Department of Health Science, Unit of Dermatology, Genoa, Italy; ${ }^{4}$ Ghent University Hospital, Department of Rheumatology, Ghent, Belgium; ${ }^{5}$ Ghent University Hospital, Department of Internal Medicine, Ghent, Belgium; ${ }^{6}$ VIB Inflammation Research Center (IRC), Unit for Molecular Immunology and Inflammation, Ghent, Belgium

Background: Fibroblast-to-myofibroblast transition and extracellular matrix (ECM) overproduction represent fundamental events in chronic inflammation, that characterise several diseases, including psoriasis $(1,2)$. Transforming growth factor- $\beta 1$ (TGF $\beta 1$ ), plays an important role as a profibrotic mediator (3).

Phosphodiesterases (PDE)4 act as proinflammatory enzymes via degradation of cAMP. PDE4 are expressed in normal skin fibroblasts (Fbs) and overexpressed in psoriatic skin Fbs and myofibroblasts (2).

Objectives: This study investigated how apremilast (an oral PDE4 inhibitor small molecule used for the treatment of psoriasis and psoriatic arthritis) might interfere with intracellular signalling for the fibroblast-to-myofibroblast transition and the synthesis of profibrotic ECM proteins induced by TGF $\beta 1$ in primary cultures of healthy human skin Fbs.

Methods: Human skin Fbs were isolated from 7 voluntary healthy subjects after signing informed consent and EC approval. The cultured Fbs were stimulated with TGF $\beta 110 \mathrm{ng} / \mathrm{ml}$ alone or in combination with apremilast $1 \mu \mathrm{M}$ and $10 \mu \mathrm{M}$ for 4,16 and 24 hours. Other aliquots of Fbs were also previously stimulated with TGF $\beta 1$ for 4 hours and then treated with apremilast $1 \mu \mathrm{M}$ and $10 \mu \mathrm{M}$ for 4,16 and 24 hours always in the presence of TGF $\beta 1$. Genes and related protein expression of $\alpha$-smooth muscle actin ( $\alpha \mathrm{SMA})$, type I collagen (COL-1) and fibronectin (FN) were investigated by qRT-PCR and Western blotting (WB). Smad proteins (the main signal transducers for receptors of TGF $\beta 1$ ) and extracellular signalregulated kinases (ERKs), which are implicated in mediating TGF $\beta 1$ effects, were investigated by WB after 15, 30 and 60 minutes of apremilast treatment combined with TGF $\beta 1$ stimulation.

Results: Apremilast significantly downregulated the phosphorylation of Smad 2 and 3 , at 15 minutes, and that of Erk1/2, after 30 minutes $(p<0.05)$, both induced by TGF $\beta 1$ stimulation in cultured skin Fbs. Apremilast significantly downregulated the TGF $\beta 1$-induced increase in the gene expression of $\alpha \mathrm{SMA}, \mathrm{COL}-1$ and $\mathrm{FN}$ at 4 and 16 hours, and the related protein synthesis at 24 hours $(\mathrm{p}<0.05)$ in cultured skin Fbs (treated in combination with TGF $\beta 1$ ). Similar effects were observed in differentiated myofibroblasts treated with apremilast.

Conclusion: Apremilast inhibited the fibroblast-to-myofibroblast transition in vitro, as well as the profibrotic activity induced by TGF $\beta 1$ in cultured skin Fbs by downregulating specific intracellular signalling pathways Smad 2/3 and Erk 1/2. These results might partially explain some of the downregulating effects on skin Fbs overactivity during treatment of skin lesions of psoriasis and that of psoriatic patients with apremilast. 